\title{
Shpinev Iu.S.
}

PHD in law, Senior Researcher Institute of State and Law of the Russian Academy of Sciences Public agreement and accession agreement: similarities and differences

\section{CORRELATION OF THE CONCEPTS «TERM»AND «CONCEPT»IN INVESTMENT RELATIONS}

This article discusses the relationship between the term and the concept. This question is one of the main questions of terminology. Examples of definitions proposed by various scientists are given. Based on the analysis, it is concluded that in modern science, the term is understood as a word denoting the concept of a special field of knowledge. Legal terms that generally fully fall under this definition have some features related to the peculiarity of jurisprudence.

Keywords: investment, investment concept, investment term, definitions, term, concept, legal terms, legal concepts

Today, the issue of attracting investment in any country is particularly acute. Russia is no exception. The legal and economic literature offers many ways to attract investors to the economy, and the problems that need to be solved for this purpose are voiced.

One of these tasks is to provide a potential investor with certain guarantees, which is solved, including transparency of investment legislation. Note that legislation cannot be considered clear and transparent if its reading causes a double interpretation of legal norms, and the key terms used in the industry have different definitions in different regulations.

In this regard, the study of the term and concept of investment is quite relevant. An important role in the relevance of the issue is played by the fact that currently law students, and young scientists, do not always understand the difference between a term, concept, definition, category. Questions of legal terminology, as well as the relationship between the term and the concept in scientific circles, both legal and linguistic science, remain relevant.

It should be noted that issues related to various areas of origin, development, functioning, as well as the relationship between the term and the concept have always been one of the most controversial areas in linguistics. At the same time, these problems are particularly acute and urgent in times of rapid growth of scientific discoveries and technical achievements, and now we live in such a rapidly changing and rapidly developing period of innovative development.

Terminology as a science was born in the mid-30s of the last century and from the very beginning there were many definitions of its fundamental subject-the term. As noted by K. Ya. Averbukh, increasing every year in quantitative terms, knowledge about the term is increasingly transformed into qualitative knowledge about its nature and functionality [1, 45].

The ability to share our thoughts and experiences with others through language is an essential attribute that has enabled us to create a special world of information and knowledge throughout our history. Terms created by people for the purpose of convenient interaction in the implementation of scientific, professional or any other special activity are the main means of expressing and fixing special knowledge. A special feature of the term is primarily its purpose, which differs from other words - to Express as accurately as possible the special concepts used in the process of scientific and professional activity and interaction.

As already noted, the question of the relationship between a term and a concept is one of the most acute in linguistics, since it is a rather complex object that combines both conceptual and linguistic principles $[2,56]$.

Many definitions of the term experts associate, among other things, with the division of views on the term from the position of D. S. Lotte and G. O. Vinokur. Thus, according to D. S. 
Lotte, terms are special words of the language [3, 15], while from the point of view of G. O. Vinokur, terms are not special words, but words with a special function.

V. P. Danilenko describes nineteen different definitions of the term [4, 83-86], B. N. Golovin gives seven definitions [5, 18-19], and the article By S. D. Shelov and sun Shufang contains more than forty definitions [6, 103-108].

In our opinion, it is not necessary to list all possible definitions in this article, and it is quite sufficient to limit ourselves to a small sample of scientists dealing with the issue under consideration.

Explanatory dictionary of modern Russian by D. N. Ushakov under the term understands a concept expressed by a word, or a word that is the name of a strictly defined concept, i.e. a special word or expression denoting something in a particular environment or profession [7].

O. S. Akhmanova, proposed a definition according to which a term is a special word or phrase of a special field of use, which serves to accurately Express a special concept and is based on the definition $[8,72]$.

According to B. N. Golovin and R. Y. Kobrin, the term is a word or phrase that has a special meaning, expresses special professional concepts and is used in the knowledge of professional, scientific and technical objects, as well as relations between them $[5,5]$.

A similar definition of the term can be found in L. A. Kapanadze, who understands the term as a unit of name in a particular field of science or technology that has a specific concept and forms a terminological system together with other concepts [9, 80]. From the point of view of L. L. Nelyubin, the term is a word used to fully Express a special concept $[10,117]$.

V. M. Leychik, based on cognitive terminology, describes a term as a lexical unit of a certain language denoting the General concept of the theory of a certain special field of knowledge or activity. [11, 31-32].

In the works of A. S. Gerd, a scientific term is defined as a unit of language that has a special terminological meaning that is expressed in verbal form and reflects as fully as possible all the essential features of a scientific concept [12, 11-12].

A. A. Yakovleva identifies three approaches to the definition of the term. In the first case, scientists try to give the term a logical definition, another part of scientists tries to determine the content of the attribute by means of its characteristic features, and a third group of scientists contrast the term with one or another negative unit. At the same time, it is noted that representatives of different Sciences also define the term in accordance with the approaches inherent in a particular science. For students of logic, it is enough to recognize the term that the word was given a strict definition. From the point of view of the philosopher, the term is a shortening of the definition, and linguists understand the term naming as a concept, while the definition is an extended interpretation of this name. As for sociologists, by the term they understand any special word, if it is related to production or science. At the same time, the presence of a strict definition is not necessary [13,88]

Based on the proposed definitions of the term, S. V. Grinev-Grinevich identifies such properties of the term as:

the specificity of the use of;

- independence from the context;

- uniqueness;

- accuracy;

- neutrality;

- conventionality;

- regulatory nature;

- definitiveness.

Given the listed properties of the term, as well as its characteristics, the scientist suggests considering the term from a pragmatic, semantic and syntactic point of view, dividing all the 
requirements for the term into requirements for meaning (lack of synonyms, unambiguity, consistency, fullness), for form (brevity, full compliance with the rules of the language, the ability to create derivatives and motivation), as well as functional requirements (internationality, esotericity, euphony, modernity and vdedrennost, implying common acceptance and use) [14, $103]$.

Most definitions of the term emphasize its connection with the concept. At the same time, it is noted that the terms relate to the concepts of a specific theory, concept, or field of knowledge that reflect the level of knowledge in this area at a given time.

The problem of the content side of a scientific concept is no less debatable than the issues related to terms. According to V. N. Borodulina, this is due to the fact that we study the concept not as a characteristic of signs, but as a form of reflection of reality at the stage of abstract thinking $[15,31]$.

According to K. I Averbukh concept, as a form of thought, is the result of generalization of objects of a certain type and mental selection of the corresponding set in accordance with the characteristics corresponding to this class. The scientist considers the content of the concept to be a set of necessary and sufficient features to distinguish one class of objects from objects of another class. Accordingly, the volume of the concept is a class of objects included in the concept) $[16,166]$.

S. V. Grinev-Grinevich considers the concept to be a special form of thought that expresses essential features of objects and phenomena of the surrounding world $[17,19]$.

A.V. Superanskaya comes to the conclusion that the concept is an element of thinking that reflects common features for a number of objects $[18,34]$.

According to $\mathrm{O}$. V. Ishaeva, the term is a lexical unit of a special language used to accurately define concepts from various scientific and professional fields [19, 108].

A.V. Ermakova emphasizes that the most important feature of the term is its ability to logically strictly define processes, properties, phenomena and objects. Based on the considered properties of the term, the author offers his own definition of the term, according to which the latter can be understood as a nominative special lexical unit that serves as the exact name of concepts. According to A.V. Ermakova, the term has a certain duality, which is manifested primarily in the fact that:

- the term should be as unambiguous as possible in different texts, but in practice, when considered outside of a specific context, it is ambiguous;

- on the one hand, the term tends to be isolated, on the other hand, it is most often associated with other words by derivation and context;

- as a General rule, a term, as a special word, needs a special definition, but in practice such a definition is often absent from the term [20, 218-220].

According to S. N. Chistyukhina, being a carrier of memory, scientific or professional on the one hand, and collective on the other, it contributes to scientific and cognitive activity and has a significant communicative dependence. Having nomitive and significative functions, the terms are intended for naming the concepts of the system not only due to the presence of the function of reflecting scientific knowledge, but also morphologically [21, 289].

E. V. Stozhok draws attention to the fact that the meaning of terms is very special concepts - the concepts of special fields of activity and knowledge. Thus, scientific concepts Express the most essential and necessary concepts of phenomena and objects and are closely related to inference, logical thinking and the essence of these phenomena [22, 80].

The concept and term in medical terminology are considered in the work of the same name by L. I. Kiseleva, where the author also comes to the conclusion that the most important thing in considering the term - concept pair is that the term expresses (names, defines, designates) special (scientific, technical, medical, etc.) concepts [23, 42]. 
Considering the definitions of the term developed in the works of linguists $\mathrm{O}$. Yu. Shmeleva offers her own definition of the term, by which she understands a special language unit, which is a word or phrase, which consists in system connections with other units of a special language that are equal in status, which serves to name and define a special concept, object or type of activity. At the same time, this language unit should be polysemantic and figurative [24, 109].

Studying the term as a linguistic expression of a special concept, M. N. Volodina asserts that the main function of the term is to Express special concepts as accurately as possible, while understanding the term as a phrase or word of a special area based on the definition used to accurately Express special concepts $[25,161]$. When considering the «concepts», it is concluded that the latter generalize our experience related to certain objects classified in the system. Referring to the definitions, the author agrees with P. A. Florensky, who called the scientific definition «explanation of concepts», which in turn meant a synthesis based on the contemplation of the reality to which the concept belongs [26, 367].

I. I. Valuitseva and I. G. Khukhuni devoted their work to clarifying the nature of the term as a special unit of the Russian language, including in terms of comparing the volume of the meaning of the term and the word. The authors, considering in detail the main features by which terms are usually distinguished from ordinary words, conclude that when considering the essential characteristics of a term in linguistics, special attention is paid to its relation to the concept $[27,13]$.

T. V. Tyurneva and N. V. Duric consider the concept and the term from the perspective of linguistic and semiotic aspects. The authors, defining the concept as one of the most important forms of thinking, emphasize its special role in the process of cognition. Then turning to the Science of logic by G. V. F. Hegel, the concept is considered as a member of the triadic relations being-essence concept. According to the philosopher, the concept embodies the essence of being. The relationship of concepts, according to Hegel, forms a conceptual network, the nodes of which are nothing more than categories [28]. The results that summarize the data of natural science are the essence of concepts that fix the essential features of things and phenomena of objective reality. Concepts do not exist in the objective world, they arise in our consciousness and replace objects, phenomena, and emotions with certain images, making the natural language of communication more capacious [29, 117]. When discussing the content of the concept, the authors agree with $\mathrm{Yu}$. V. Ivlev, who defines the concept as a thought in which objects are separated from a certain set and generalized into one class according to a system of features common only to them $[30,115]$.

Analyzing the current issues of terminology studies in other countries, V. N. Nasirov and T. S. Kirillova conclude that the definition of a term through a word that denotes a special concept does not cause significant disagreements not only among Russian scientists, but also among their foreign colleagues. The authors emphasize the increased interest in the cognitive direction in terminology in recent years, according to which the term is recognized as a language unit that appears as a result of professional cognition and communication [31, 166-168].

Thus, analyzing the opinions of scientists presented above, we can state that in modern research, the term is understood as a word or phrase denoting the concept of a special field of knowledge or activity.

In this case, each term refers to a concept from a special field, but not every concept has its own term.

As for the relation between concept and category, we can state that every category is a concept, but not every concept is a category.

Legal terms that generally fully fall under this definition have some features related to the peculiarity of jurisprudence. 
With regard to investment, the investment is the term. As for the concept of investment, it is proposed in regulations and scientific research in the form of definitions.

It should be noted that until now, investment regulations contain different concepts of investment, which is not at all conducive to improving the investment climate.

\section{References}

1. Averbukh K. Ya. Terminological variation // Questions of linguistics. 1986. No. 6. Pp. 38-50. 2. Morozova L. A. term Knowledge: Basic methods / L. A. Morozova. M. GNO «Prometheus» MPSU. 2014. 144 p.

3. Tatarinov V. A. History of Russian terminology in 3 vols. 2. Directions and methods of terminological research: Essay and textbook.Moscow Lyceum. 1995.334 p.

4. Danilenko V. P. Russian terminology. Experience of linguistic description. M. Nauka 1977. $246 \mathrm{p}$.

5. Golovin B. N., Kobrin R. Yu. Linguistic foundations of the doctrine of terms: a textbook for philologists. spec. vuzov. / M. Higher School. 1987. 104 p.

6. Shelov S. D., Shufang Sun. The term as the main unit of terminology: diversity of definitions and unity of understanding // Questions of linguistics. 2017. no. 6. Pp. 102-114.

7. Ushakov D. N. Explanatory dictionary of the modern Russian language // [Electronic resource]. Mode of access: http://ushakovdictionary.ru/word.php?wordid=76767. (accessed 11.09.2020).

8. Ahmanova O. S. Extralinguistic and intra-linguistic factors in the functioning and development of the language / Theoretical problems of modern Soviet linguistics: collection of articles / ed. Board: Acad. V. V. Vinogradov (ed.) and others. M. Nauka. 1964. Pp. 69-74.

9. Kapanadze L. A. On the concepts of term and terminology / Development of the vocabulary of the modern Russian literary language. M. Nauka, 1965. Pp. 75-85.

10. Nelyubin L. L. Introduction to translation techniques (cognitive theoretical and pragmatic aspect): textbook. manual. M. flint: Science. 2009. 216 p.

11. Leychik V. M. terminology: subject, methods, structure. Ed. 4-E. M. Librokom. 2009. 256 p.

12. Gerd A. S. Formation of the terminological structure of the Russian biological text. L.

Nauka. 1981. 112 p.

13. Yakovleva A. A. On the concept of «term» in modern linguistics // Interexpo Geo-Siberia. 2014. Vol. 6. No. 2. Pp. 88-94.

14. Grinev-Grinevich S. V. Terminovedenie. M. Akademiya. 2008. 304 p.

15. Borodulina $\mathrm{N}$. Yu. Metaphorical representation of economic concepts as an object science of logic. M. Mysl. 1998. 172 p. semiotic analysis: monograph /Tambov. Charter. 2007. 184 p.

16. Averbukh K. Ya. General theory of the term / Ivanovo. 2004. 252 p.

17. Grinev-Grinevich S. V. Fundamentals of anthropolinguistics (to the linguistic foundations of the evolution of thinking): textbook / M. Sputnik +. 2005. $114 \mathrm{p}$.

18. Superanskaya A.V. General terminology: questions of theory / M. Nauka. 1989. 246 p.

19. Ishayev O. V. a term as a lexical unit special language/ Cultural linguistics. 2019. No. 13. Pp. 105-110.

20. Ermakova A.V. Nature of the term // Bulletin of the Lobachevsky University of Nizhny Novgorod. 2018. No. 2. Pp. 218-223.

21. Chistyukhina S. N. on some features and functions of the term // Toria and practice of social development. 2011. no. 1 p. 287-289.

22. Stozhok E. V. Term, concept, meaning / / Omsk scientific Bulletin. 2011. Pp. 79-81.

23. Kiseleva L. A. Term and concept in medical terminology / / Humanities research. 2015. No. 3 (55). Pp. 41-46. 
24. Shmeleva O. Yu. Modern approaches to the definition of the term as a special language unit // Bulletin of the Leningrad state University named after A. S. Pushkin. 2010. Vol. 1. No. 3. Pp. 104-114.

25. Volodina M. N. Term as a language expression of a special concept / / Stephanos. 2019. No. 4 (36). Pp. 160-166. DOI 10.24249/2309-9917-2019-36-4-160-166.

26. Florensky P. A. Term // Tatarinov V. A. History of Russian terminology. M. 1994. Pp. 369371.

27. Valuitseva I. I., Khukhuni I. G. Term and word: correlation of concepts / / Bulletin of the Moscow state regional University. Series: Linguistics. 2019. no. 5. Pp. 6-16. DOI:

10.18384/2310-712X-2019-5-6-16.

28. Gegel G. V. F. Nauka logiki. m. Mysl. 1998. 172 p.

29. T. V. Tyurneva Shurik N. V. Concept vs. term: linguistic and semiotic aspect //Modern research of social problems. 2017 Vol. 9. No. 1. Pp. 115-125.

30. Ivlev Yu. V. Logika. / M. Logos. 2001. 272 p.

31. Nasirova V. N., Kirillova T. S. Term and concept / Modern problems of natural Sciences and Humanities. Proceedings of the XXIV international scientific and practical conference. Research and information publishing center "Institute for strategic studies". 2015. Pp. 166-168. 